\title{
O PRINCÍPIO DA EDUCAÇÃO ESPECIAL EM NAVIRAÍ/MS: PROFESSORAS QUE CONTAM A HISTÓRIA
}

\author{
THE PRINCIPLE OF SPECIAL EDUCATION IN NAVIRAÍ/MS: \\ TEACHERS WHO TELL THE HISTORY
}

\author{
Josiane Peres Gonçalves ${ }^{1}$ \\ Giovani Ferreira Bezerra² \\ Rute Santos Novais ${ }^{3}$
}

\begin{abstract}
RESUMO: O presente estudo refere-se aos trabalhos iniciais da Educação Especial em Naviraí e visa compreender como era oferecida a educação formal às crianças com deficiência, desde o surgimento do município, em 1963, quando não havia escolas especializadas em atendê-las, até 1986, ano em que surge o Centro de Educação Especial Naviraiense (CEDEN), que atualmente funciona juntamente com a Associação de Pais e Amigos dos Excepcionais (APAE). Apresenta um breve histórico de Naviraí, da Educação Especial no Brasil e a legislação que rege a Educação Especial no país. A pesquisa de campo, de natureza qualitativa, foi realizada por meio da gravação de entrevista com duas professoras que trabalharam com salas especiais no período investigado e também contribuíram com a implantação da APAE no município. Os resultados indicam que, embora as primeiras salas de aula tenham surgido em 1958, foi somente em 1976 que houve a implantação de uma sala, anexa à escola municipal Marechal Rondon, voltada ao atendimento de crianças com deficiência, sendo todas matriculadas na mesma turma, apesar de suas especificidades. A formação das duas professoras, para trabalhar com esses alunos, consistia em um curso realizado em Cuiabá, alguns meses antes da abertura da classe especial. Evidencia-se que Naviraí acompanhou - sistema educacional vigente no país, visto que as salas especiais foram implantadas no mesmo período em que começou a surgir, no Brasil, um maior investimento relacionado à educação especial.
\end{abstract}

Palavras-chave: Educação especial. História. Atendimento educacional especializado.

\footnotetext{
1 Professora permanente do Programa de Pós-Graduação Mestrado em Educação do Campus do Pantanal da Universidade Federal de Mato Grosso do Sul, professora permanente do Programa de Pós-Graduação Mestrado e Doutorado em Educação da Faculdade de Educação e professora dos cursos de licenciatura em Ciências Sociais e Pedagogia do Campus de Naviraí. Doutora em Educação pela Pontifícia Universidade Católica do Rio Grande do Sul.

2 Professor da Universidade Federal de Mato Grosso do Sul. Doutor em Educação pela Universidade Federal da Grande Dourados.

${ }^{3}$ Graduada em Pedagogia pela Universidade Federal do Mato Grosso do Sul.
} 
ABSTRACT: The present study refers to the initial works of special education in Naviraí and aims to understand how formal education was offered to children with disabilities since the foundation of the city in 1963, when there were no schools specialized in attending these children, until 1986, year in which the Centro de Educação Especial Naviraiense (CEDEN) was founded, which currently works together with the Associação de Pais e Amigos dos Excepcionais (APAE). It presents a brief history of Naviraí, the historical panorama of special education in Brazil and the legislation for special education in the country. The qualitative field research was carried out by recording interviews with two teachers who worked with special classes during the investigation period and also contributed to the implementation of the APAE in the city. The results indicate that, although the first classrooms appeared in 1958, it was only in 1976 that a room was installed, attached to the Marechal Rondon municipal school, directed to taking care of children with disabilities, all of them enrolled in the same class, despite their specificities. The training of the two teachers to work with these students consisted of a course held in Cuiabá, some months before the opening of the special class. It is evident that Naviraí accompanied the current educational system at the time in the country, since the special rooms were implanted in the same period in which a greater investment related to special education began to appear in Brazil.

Key words: Special education. History. Specialized educational assistance.

\section{Introdução}

Ao se pensar na Educação Especial desenvolvida em Naviraí, a primeira ideia que se tem é que a Associação de Pais e Amigos dos Excepcionais (APAE) é o local apropriado para atender as pessoas com deficiência. Afinal, são mais de trinta anos de existência no município, uma vez que foi fundada em 1977, nove anos antes do Centro de Educação Especial Naviraiense (CEDEN). Desse modo, fica até difícil imaginar como era e se havia algum tipo de atendimento especializado às pessoas com deficiência antes da implantação dessa entidade.

Foi justamente essa situação que motivou as seguintes indagações: será que havia educação formal para pessoas com deficiência antes da criação da APAE em Naviraí? Se havia, como era essa oferta e quem desenvolvia esse trabalho? A busca por possíveis respostas para tais questionamento é o que justifica a realização desta pesquisa.

A intenção é fazer um estudo histórico da Educação Especial no município de Naviraí, a fim de entender como era oferecida a educação 
formal às crianças com deficiência, no período que vai de 1963 até 1986, ano da criação do CEDEN, que, atualmente, funciona juntamente com a APAE. Espera-se, então, compreender como se dava e onde era ofertada a educação escolar de pessoas com deficiência antes da criação dessa escola especializada no município, como era o ensino, quem eram os professores, bem como se o espaço físico era adequado aos alunos, entre outros aspectos.

Buscando obter as informações almejadas, a metodologia utilizada consiste em um estudo bibliográfico e uma pesquisa de campo norteada pela perspectiva de histórias de vida, realizada por meio de entrevista com duas professoras que atuaram na Educação Especial, no município, antes da implantação da APAE local e de sua escola, o CEDEN. Os resultados obtidos são apresentados logo após a apresentação da abordagem teórica e metodologia da pesquisa.

\section{Breve Histórico de Naviraí}

A cidade de Naviraí, situada no interior do estado de Mato Grosso do Sul (MS), em sua porção meridional, começou a ser colonizada em 1952, período em que esse Estado ainda não existia e seu território pertencia ao estado de Mato Grosso (MT). Ariosto Riva chegou com alguns companheiros para fundar a Colonizadora Vera Cruz Ltda e então surgiu o primeiro nome da cidade, na época um pequeno povoado, conhecido como "Vera Cruz", que iniciou devido à implantação de algumas madeireiras (IBGE, 2017).

Com o aumento da população, as primeiras salas de aula começaram a ser construídas em 1956, mas foi em 1958 que o povoado se tornou distrito do município de Caarapó e, então, o nome foi alterado para Naviraí, que significa, em guarani, "Pequeno Rio Impregnado de Arbustos Roxos" (IBGE, 2017). Cinco anos depois, no dia 11 de novembro de 1963, Naviraí foi emancipada e se tornou município, e esta data passou a ser reconhecida como dia do aniversário municipal. 
Nesse período, Naviraí ainda pertencia ao território Mato-Grossense e todos os problemas municipais eram resolvidos em Cuiabá, capital de MT. Somente em 11 de outubro de 1977 é que ocorre a divisão dos Estados, surgindo, assim, o estado de MS, cuja capital passou a ser Campo Grande, localizada há 370 quilômetros de Naviraí. Tais contingências históricas e o próprio isolamento geográfico dificultaram, de imediato, a criação e oferta de serviços educacionais especializados para pessoas com deficiência nessa cidade.

Dessa forma, mediante a realização da presente pesquisa, buscamos compreender, justamente, como se iniciou a oferta da Educação Especial institucionalizada em Naviraí, entre 1963, período da emancipação política do município, e 1986, quando, em caráter de sua escola especializada, sendo a primeira e, até hoje, única instituição com essa característica na cidade. Logo, o foco do artigo é investigar o trabalho relativo à Educação Especial, realizado por um período de 23 anos, em Naviraí. Antes, porém, entendemos que é importante refletir sobre a Educação Especial em âmbito nacional, conforme apresentado na sequência.

\section{Panorama histórico da Educação Especial no Brasil}

A História da Educação para pessoas com deficiência no Brasil começou em 1854, com a criação do Instituto Imperial dos Meninos Cegos ${ }^{4}$ e, em 1857, houve a criação do Imperial Instituto dos Surdos-Mudos ${ }^{5}$, ambos fundados no Rio de Janeiro, capital do Império, passando, então, a se expandir para outras cidades no século XX. Nesse contexto, a educação escolar para pessoas com deficiência era oferecida somente para cegos e surdos. Indivíduos com outros tipos de deficiência eram internados em hospícios e hospitais ou reclusos em casa pela família, pois a pessoa com

\footnotetext{
4 Criado em 1854, foi um grande marco para a Educação Especial, juntamente com o Imperial Instituto dos Surdos-Mudos, considerando o contexto da época. Atualmente, se chama Instituto Benjamin Constant (IBC).

${ }^{5}$ Iniciou-se sob direção do francês Edouard Hüet. Atualmente se chama Instituto Nacional de Educação de Surdos (INES).
} 
deficiência foi marginalizada e ignorada por muito tempo, inclusive pela igreja (LANNA JúNIOR, 2010).

Somente no ano de 1904 foi criado o Pavilhão-Escola Bournevillé, que seguia o método médico-pedagógico de Bourneville, em que as crianças eram separadas em três grupos principais: "[...] $01^{0}$ de creanças idiotas, cretinas, epiléticas ou não, mas 'inválidas'; o 20 de creanças idiotas, cretinas ou não, mas "válidas" e o $3^{0}$ de creanças apropriadas, válidas, imbecis, retardadas, instáveis, perversas, epiléticas e histéricas ou não" (MÜLLER, 2000, p. 85). A partir da separação dos grupos, eram trabalhadas atividades de acordo com as especificidades de cada um deles, desde atividades escolares simples a atos de higiene e oficinas.

Em 1926, cria-se, no Rio Grande do Sul, o Instituto Pestalozzi de Canoas, inspirado em ideais do suíço Johann Heinrich Pestalozzi, que ganhou força após a chegada de Helena Antipoff, educadora e psicóloga russa. Ela chegou ao Brasil, em 1929, para trabalhar na Escola de aperfeiçoamento de Belo Horizonte-MG. Em 1932, Antipoff fundou a Pestalozzi em Belo Horizonte e, por meio de sua influência, a instituição passou a se expandir por todo país a partir de 1945, possuindo, atualmente, cerca de 150 unidades. Antipoff foi uma grande defensora da causa das crianças com deficiência. Devido a seu trabalho e influência, as nomenclaturas dadas a pessoas com deficiência intelectual na época "deficiência mental" e "retardo mental" - foram substituídas pela palavra "excepcional", atualmente designada "deficiência intelectual", condição que significa um déficit no funcionamento do intelecto (LANNA JUNIOR, 2010, p. 26).

Segundo Capellini e Mendes (2006), na década de 1930, com o movimento Escola Nova, ocorre um aumento de interesse pela educação no país, com propostas que buscavam a diminuição da desigualdade escolar, o que influenciou e estimulou mudanças na educação de pessoas com deficiência.

\footnotetext{
${ }^{6}$ Desiré Magloire Bourneville, médico alienista que dedicou a carreira a pesquisar e tratar doenças mentais e nervosas infantis.
} 
No período de 1937 a 1945, o Brasil passa pelo Estado Novo, sendo observado um retrocesso no processo de democratização do ensino por meio de uma política centralizadora da Educação, com um forte controle estatal em todos os setores sociais e um certo fortalecimento do Ensino Superior (CAPELLINI; MENDES, 2006). Após essa fase de investimentos, em que a educação teve um foco maior no ensino superior, no ano de 1958 surge, novamente, um maior interesse no atendimento educacional a pessoas com deficiência, com apoio às campanhas nacionais que atuavam nessa área (CAPELLINI; MENDES, 2006).

Helena Antipoff, além de participar ativamente de várias ações em benefício das pessoas com deficiência, também fez parte de movimentos determinantes para a implantação da Associação de Pais e Amigos dos Excepcionais (APAE), que ocorreu em 1954, conforme Mendes (2010). Assim, a primeira APAE foi fundada no Rio de Janeiro, pela iniciativa de uma americana, mãe de uma criança com deficiência intelectual, e se expandiu por todo país. As organizações apaeanas constituem uma rede de atendimento à pessoa com deficiência de expressiva capilaridade na sociedade, que presta serviços de educação, saúde e assistência social. O atendimento é voltado para as pessoas com deficiência intelectual e múltipla. Trata-se de uma sociedade filantrópica, que presta apoio a instituições que oferecem ensino e assistência a pessoas com deficiência. Em 1962, funda-se a Federação Nacional de APAEs (Fenapaes) (LANNA JUNIOR, 2010).

A criação dessas sociedades em prol da educação de pessoas com deficiência fez com que várias outras instituições filantrópicas com propostas parecidas fossem surgindo. Não obstante, até o ano de 1956, todas essas iniciativas foram feitas por pessoas da sociedade civil que estavam preocupadas com a educação das crianças com deficiência, e a ajuda recebida do governo era pouca ou quase inexistente (NAHIRNEI; HEROLD, 2009).

A partir de 1957, o governo federal assume a responsabilidades pela Educação Especial com a criação de campanhas educacionais, sendo a primeira delas a Campanha para a Educação do Surdo Brasileiro (CESB), 
com Decreto Federal no 42.728, de 3 de dezembro de 1957 (MAZZOTA, 2005), que estabelece, a partir desta campanha, o fornecimento de educação e assistência aos deficientes auditivos e da fala.

Em 1958, vinculado ao Instituto Benjamin Constant, cria-se a Campanha Nacional de Educação e Reabilitação de Deficientes da Visão, pelo Decreto Federal no 44.236, de $1^{\circ}$ de agosto daquele ano. Essa campanha tinha o dever de promover educação e reabilitação a todos os deficientes visuais da época, em todas as etapas do ensino escolar. Em 1960, a Campanha desvincula-se do Instituto e passa a ser de responsabilidade direta do Ministro do Estado da Educação e Cultura, transformando-se em Campanha Nacional de Educação de Cegos (C.N.E.C.), sendo que todas as alterações foram firmadas no Decreto no 48.252, de 31 de maio de 1960. Também, em 1960, cria-se a Campanha Nacional de Educação e Reabilitação de Deficientes Mentais (CADEME), pelo Decreto no 48.961, de 22 de setembro de 1960. Essa campanha também foi dirigida pelo Ministro da Educação e Cultura, com o objetivo de estabelecer, em todo o país, educação, treinamento, reabilitação e assistência educacional a crianças com deficiência intelectual, ditas como retardadas e/ou deficientes mentais na época, de qualquer sexo e idade (MAZZOTTA, 2005).

As classes especiais começaram a ser implantadas desde 1927, e cada unidade consistia em uma sala presente em escolas de ensino comum. A classe recebia alunos com deficiência e com atraso escolar, seguindo um currículo próprio, adaptado para atender a esses alunos (LIMA, 2010).

Na década de 1970 , os olhares políticos se voltam para a educação especial, aumentando, consideravelmente, o número de classes especiais no país. Segundo Mendes (2010), havia instituições especializadas no ensino especial, sendo a maioria em rede privada, mas este serviço em classes especiais, funcionando no interior das escolas comuns, ainda era o mais procurado.

Ainda assim, Capelline e Mendes (2006) relatam que essas classes eram utilizadas mais para atender alunos considerados problemáticos e com dificuldades de aprendizagem, fugindo do propósito de atender crianças 
com deficiência. "É importante que se saliente que as escolas e classes especiais passaram a ter um elevado número de alunos com 'problemas' e que não necessitariam estar ali" (ROGALSKI, 2010, p. 5).

Dessa maneira, a proposta de integração que a criação das classes especiais visava ocorreu de maneira contrária, evidenciando a segregação das crianças com deficiência ou outras necessidades educacionais especiais. $\mathrm{Na}$ década de 1970, com esse avanço nas classes especiais, a Educação Especial ganha maior visibilidade e o Ministério da Educação passa a reconhecer que pessoas com deficiência precisavam de atenção especial na escola, no lar e na sociedade (CAPELLINI; MENDES, 2006). Nessa conjuntura,

Em 1973, o MEC cria o Centro Nacional de Educação Especial - CENESP, responsável pela gerência da Educação Especial no Brasil, que, sob a égide integracionista, impulsionou ações educacionais voltadas às pessoas com deficiência e às pessoas com superdotação, mas ainda configuradas por campanhas assistenciais e iniciativas isoladas do Estado (BRASIL, 2008, p. 2).

Apesar da visibilidade alcançada até esse período, a oferta do ensino fornecido a pessoas com deficiência ainda não era organizada de forma satisfatória, fazendo com que as classes especiais continuassem a existir. Ao final dessa mesma década, começam a surgir os primeiros cursos superiores na área da Educação Especial (MENDES, 2010).

Em 1980, inicia-se a busca por integração e por direitos iguais para as pessoas com deficiência, baseada em movimentos que já vinham acontecendo na Europa e Estados Unidos. O intuito passou a ser valorizar cada ser humano, respeitando as individualidades e necessidades, objetivo que ainda vem sendo perseguido na realidade nacional (CAPELLINE; MENDES, 2006).

A Constituição Federal Brasileira de 1988 traçou as linhas mestras visando à democratização da educação brasileira e trouxe dispositivos para tentar erradicar o analfabetismo, universalizar o atendimento escolar, melhorar a qualidade do ensino, implementar a formação para o trabalho e a formação humanística, científica e tecnológica do país. Ela assegurou que a educação de pessoas com deficiência deveria ocorrer, preferencialmente, 
na rede regular de ensino, e garantiu ainda o direito ao atendimento educacional especializado (BRASIL, 1988).

Sendo assim, a Constituição Federal de 1988 determina que a educação de pessoas com necessidades educacionais especiais deve considerar o atendimento especializado, de preferência no ensino regular, em escolas públicas, firmando-se na Lei de Diretrizes e Bases de 1996. Face ao exposto, a partir dos direitos alcançados com a Constituição Federal de 1988, o ensino escolar no país passa por uma reforma que busca alcançar uma educação de qualidade, acessível a todos. Na sequência, os anos de 1990 ficam marcados pela busca da universalização do ensino escolar e da educação inclusiva, tanto no ensino regular quanto na Educação Especial (MENDES, 2010).

Em 1994, a Educação Inclusiva dá um grande passo com a Declaração de Salamanca, que preconiza que a escola deve atender alunos de todas as classes, cores, religiões, etnias, com deficiência ou não, oferecendo ensino de qualidade de forma igualitária para todos (SILVA, 2009).

No ano de 1998, o Ministério da Educação (MEC) lança um documento contendo alterações que devem ser feitas nos Parâmetros Curriculares Nacionais (PCNs) para atender alunos com deficiência. Em 2001, são lançadas, também pelo MEC, as Diretrizes Nacionais para a Educação Especial na Educação Básica, vigentes até os dias atuais (RODRIGUES, 2008), dando margem a proposição de novas orientações para a Educação Especial em uma perspectiva inclusiva.

\section{Leis que regem a Educação Especial no Brasil}

A educação escolar no Brasil se iniciou com a concepção de que a escola era um privilégio de grandes senhores da elite da época, e somente as pessoas deste grupo poderiam ter acesso à educação. Muito lentamente, já que pessoas consideradas "fora dos padrões" acabaram por ser privadas do ensino nesta época, a educação tornou-se democrática, de direito de 
todos e, obrigatoriamente, ofertada gratuitamente pelo governo. No bojo dessas contradições e cerceamentos, a Educação Especial, em particular,

[...] se organizou tradicionalmente como atendimento educacional especializado substitutivo ao ensino comum, evidenciando diferentes compreensões, terminologias e modalidades que levaram à criação de instituições especializadas, escolas especiais e classes especiais. Essa organização, fundamentada no conceito de normalidade/anormalidade, determina formas de atendimento clínico-terapêuticos fortemente ancorados nos testes psicométricos que, por meio de diagnósticos, definem as práticas escolares para os estudantes com deficiência (BRASIL, 2008, p. 1-2).

Em 1961, as pessoas com deficiência passam a ser integradas ao ensino regular, em escolas públicas e privadas, que receberam auxílio do governo no atendimento aos "excepcionais"", a fim de integrá-los na sociedade. Esta mudança foi alicerçada pela Lei no 4.024/61, nos artigos 88 e 89, e pela então primeira Lei de Diretrizes e Bases da Educação Nacional (BRASIL, 1961).

Face ao exposto, dez anos após sua criação, a Lei no 4.024 sofre sua primeira alteração, registrada na Lei no 5.692/71, preconizando, em seu Art. 90, um tratamento especial para os "[...] alunos que apresentem deficiências físicas ou mentais, os que se encontrem em atraso considerável quanto à idade regular de matrícula e os superdotados" (BRASIL, 1971) o que, para Brasil, não garantiu uma educação realmente inclusiva, segregando algumas deficiências e reforçando a permanência das classes especiais (BRASIL, 2008).

Em 1988, a Constituição Federal vem firmar a educação como direto de todos, sendo dever do Estado garantir igualdade de acesso e permanência no ensino escolar e dever dos pais matricular seus filhos, sendo prevista, também, na Lei no 8.069/90, relativa ao Estatuto da Criança e do adolescente (BRASIL, 1988; 1990).

Como garantia de acesso ao ensino escolar, a Lei no 7.853/89 vem definir a Educação Especial como uma modalidade educativa oficial do país.

\footnotetext{
7 Palavra que substituiu os termos "deficiência mental" e "retardo mental" por influência de Helena Antipoff e, mais tarde, foi substituída por alunos portadores de necessidades educacionais especiais, recomendando-se, atualmente, o uso da expressão pessoa com deficiência, haja vista a estigmatização trazida pela ideia de "portador".
} 
Esse entendimento é reafirmado em 1996, quando surge a Lei no 9.394/96, estabelecendo em seu Art. 58 que a Educação Especial é uma "[...] modalidade de educação escolar oferecida preferencialmente na rede regular de ensino, para educandos com deficiência, transtornos globais do desenvolvimento e altas habilidades ou superdotação" (BRASIL, 1996). Assim, o ensino deve ser ofertado em classes comuns e contando com o apoio especializado quando necessário.

Posteriormente, a Resolução CNE/CEB no 2/2001, nas Diretrizes Nacionais para Educação Especial na Educação Básica, em seu Art. 30, vem firmar que:

\begin{abstract}
Por educação especial, modalidade da educação escolar, entende-se um processo educacional definido por uma proposta pedagógica que assegure recursos e serviços educacionais especiais, organizados institucionalmente para apoiar, complementar, suplementar e, em alguns casos, substituir os serviços educacionais comuns, de modo a garantir a educação escolar e promover o desenvolvimento das potencialidades dos educandos que apresentam necessidades educacionais especiais, em todas as etapas e modalidades da educação básica (BRASIL, 2001).
\end{abstract}

A Resolução CNE/CEB de 2001 estabelece, também, que os estudantes com necessidades educacionais especiais devem ser matriculados nos sistemas comuns de ensino, sendo dever da escola receber a todos e se organizar para o atendimento a tais alunos, garantindo qualidade na escolarização de todos (BRASIL, 2001).

Em 2002, a Língua Brasileira de Sinais (Libras) é reconhecida como meio legal de comunicação e expressão, e passa a ser disciplina obrigatória em cursos de nível médio ou superior, no âmbito da Educação Especial, por meio da Lei no 10.436/02. Em 2005, o decreto no 5.626 regulamenta essa lei, dizendo que a Libras deve ser inserida como disciplina curricular obrigatória nos cursos de formação de professores para o exercício do magistério, em nível médio e superior, e nos cursos de fonoaudiologia, de instituições de ensino públicas e privadas, do sistema federal de ensino e dos sistemas de ensino dos estados, do distrito federal e dos municípios (BRASIL, 
2005). Ainda em 2002, a portaria no 2.678/02 regulamenta o uso do Sistema Braille, seu ensino e difusão em todas as modalidades de ensino (BRASIL, 2002).

No ano de 2007, o Plano de Desenvolvimento da Educação (PDE) recomenda que escolas possuam acessibilidade em sua estrutura física, assim como implantação de salas de recursos multifuncionais e a formação docente para o atendimento educacional especializado (BRASIL, 2008). No ano de 2008, a Política nacional de Educação Especial, na perspectiva da educação inclusiva, enfatiza o caráter de processo da inclusão educacional desde o título: "na perspectiva da" (BRASIL, 2008). Tal política, pautada em outros documentos legais e:

Ancorada nas deliberações da Conferência Nacional de Educação - CONAE/ 2010, a Lei no 13.005/2014, que institui o Plano Nacional de Educação - PNE, no inciso III, parágrafo 10, do Art. 80, determina que os Estados, o Distrito Federal e os Municípios garantam o atendimento as necessidades específicas na educação especial, assegurando o sistema educacional inclusivo em todos os níveis, etapas e modalidades (BRASIL, 2008, p. 6-7).

A Lei no 13.146 de 2015, com base na Convenção sobre os direitos das pessoas com deficiência, aborda, ainda, o direito à educação para esse segmento, que deve ser inclusiva e de qualidade em todos os níveis de ensino; bem como visa garantir condições de acesso, permanência, participação e aprendizagem, por meio da oferta de serviços e recursos de acessibilidade que eliminem as barreiras (BRASIL, 2015). No ano seguinte, a Lei no 13.409, que altera a Lei no 12.711 , dispõe sobre a reserva de vagas para pessoas com deficiência nos cursos técnico de nível médio e superior das instituições federais de ensino, sendo incluídas pelo sistema de cotas (BRASIL, 2016).

Sendo assim, fica patente o direito da pessoa com deficiência à educação escolar, sendo dever do Estado garantir esse ensino em rede pública, em classe comum, com a disponibilização de apoios, serviços e suportes especializados para atender as especificidades de cada aluno, com 
vistas a garantir seu desenvolvimento. Todavia, é preciso ressaltar que, apesar das conquistas legais elencadas anteriormente, é preciso avançar na concretização desses direitos, de modo que deixem de ser garantias formais e se convertam em práticas inclusivas.

É justamente por isso que (re)visitar a História da Educação Especial nos possibilita (re)dimensionar os avanços que existiram, ou não, ao longo desses anos, desde as primeiras iniciativas oficiais no Brasil Império ao passado mais recente, possibilitando perspectivar uma linha de ação mais equânime no presente e no futuro. Nesse sentido, buscamos as histórias e memórias de professoras atuantes na Educação Especial, conforme descrito nos procedimentos metodológicos seguintes, pois entendemos ser esta uma lente que permite o cruzamento das dimensões oficiais, legais e subjetivas na compreensão e problematização histórica desse campo.

\section{Procedimentos Metodológicos}

Este estudo foi realizado por meio de pesquisa de natureza qualitativa, a qual preocupa-se em apresentar características aprofundadas da realidade do entrevistado, sem se basear em aspectos numéricos, pois os fatos analisados em uma pesquisa qualitativa não podem ser quantificados (SILVEIRA; GERHARDT, 2009).

Dessa forma, foi feita a opção por realizar a pesquisa segundo a perspectiva de histórias de vida porque, ao relatar sobre o histórico da Educação Especial em Naviraí, entre 1963, quando ocorreu a emancipação municipal, e 1986, quando houve a criação do CEDEN, as duas professoras entrevistadas, que trabalharam com classes especiais nesse período, também narravam sobre suas próprias histórias e experiências profissionais. Nesses termos,

As histórias de vida adotam e comportam uma variedade de fontes e procedimentos de recolha, podendo ser agrupadas em duas dimensões, ou seja, os diversos "documentos pessoais" (autobiografias, diários, cartas, fotografias e objetos pessoais) e as "entrevistas biográficas", que podem ser orais ou escritas. [...] As histórias de vida são, 
atualmente, utilizadas em diferentes áreas das ciências humanas e da formação, através da adequação de seus princípios epistemológicos e metodológicos a outra lógica da formação do adulto, a partir dos saberes tácitos ou experienciais e da revelação das aprendizagens construídas ao longo da vida como uma metacognição ou metarreflexão do conhecimento de si (SOUZA, 2006, p. 24-25).

Corroborando tais pressupostos, Josso (2007, p. 433) salienta que esse tipo de investigação científica, relativa às histórias de vida, refere-se ao entrelaçamento de um destino que é visto como:

[...] sociologicamente, culturalmente e historicamente previsível, de uma memória personalizada desse destino potencial e de um imaginário sensível original capaz de seduzir, de tocar emocionalmente, de falar, de interpelar outras consciências ou ainda de convencer racionalmente.

O instrumento utilizado para a realização da coleta de dados consistiu em um roteiro semiestruturado, que serviu de base para a gravação das entrevistas com as participantes da pesquisa. Para Silveira e Gerhardt (2009), esse tipo de instrumento investigativo é importante porque o pesquisador pode instigar o entrevistado a falar livremente sobre o assunto, havendo a possibilidade de surgir novas questões relevantes e que não estavam no roteiro previamente elaborado.

Participaram do estudo duas professoras que trabalharam com salas especiais em Naviraí durante o período histórico investigado (1963-1986). A primeira entrevistada foi a professora Maria Luiza Santana (neste estudo, identificada por SANTANA), vinda do Paraná, onde já atuava como docente em uma APAE, para trabalhar na classe especial de Naviraí. Ela contribuiu, também, com a implantação da APAE em Naviraí. A segunda entrevistada foi a professora Lourdes Elerbrok (neste estudo, identificada por ELERBROK), que, em 1976, foi designada a trabalhar em uma classe especial, após realizar um curso profissionalizante na área em Cuiabá, ainda antes do desmembramento do Estado de Mato Grosso, ocorrido no ano seguinte.

O contato com as entrevistadas foi feito por meio de uma rede social, sendo, então, agendados a data, horário e local em que ocorreria a entrevista, de acordo com a disponibilidade das participantes, assim ambas optaram para que os encontros fossem realizados em suas residências. As 
perguntas e interferências realizadas pela pesquisadora serão identificadas pela palavra "Pesquisadora", quando necessário.

Os dados obtidos mediante a realização da pesquisa de campo foram transcritos, sistematizados e analisados, sendo, então, apresentados e discutidos com base em autores que estudam a temática relativa à Educação Especial.

\section{Resultados e Discussão}

Para melhor compreensão da análise dos dados, estes foram organizados da seguinte maneira: primeiramente a pergunta realizada no momento da entrevista, em seguida, a respostas das entrevistadas, buscando-se o contraponto com a concepção de autores que falam sobre o assunto e, assim, sucessivamente.

Dessa forma, a primeira pergunta refere-se ao local em que os alunos com deficiência eram atendidos entre os anos de 1963 e 1986, sendo obtida a seguinte resposta:

Quando cheguei em Naviraí, em 1977, os alunos eram atendidos na classe especial do colégio Marechal Rondon. Era uma classe especial, que tinha a professora Olivia e a professora Lourdes Elerbrock. Aí, eu cheguei para trabalhar junto e como eu já tinha especialização na área e eu já trabalhava em APAE no estado do Paraná, então eu achei por bem criar a APAE na época, né. Porque na verdade a APAE é uma associação, ela é uma entidade mantenedora de uma escola, ela é uma entidade que mantém Escola Especial, sabe? Atendimento especializado (SANTANA).

O apontamento da participante da pesquisa sobre a função da APAE está relacionado com a afirmação de Lanna Júnior (2010) de que essas instituições especializadas prestam serviço de apoio à educação e saúde a pessoa com deficiência. De forma semelhante, a professora Elerbrok mencionou que, antes de 1986, "Não existia atendimento, só tinha uma classe especial na escola Marechal Rondon e nem foi em 1963, foi a partir de 1976 que começou a classe especial". 
É possível perceber, mediante os relatos das professoras, que o ensino de crianças com deficiência começou em uma classe especial, de uma escola do município, em meados da década de 1970, indicando que Naviraí acompanhou o mesmo ritmo do país. Para Capelline e Mendes (2006), com a criação de serviços em prol da Educação Especial que ocorreu nos anos finais da década de 1960, houve uma grande oferta de ensino a pessoas com deficiência em classes especiais e salas de recursos nos anos de 1970. Mendes (2010) também afirma que as classes especiais funcionavam em escolas regulares, em sua maioria estaduais.

Em Naviraí, conforme os relatos das entrevistadas, a classe especial funcionava em uma sala da Escola Municipal Marechal Rondon ${ }^{8}$, a partir da qual Santana lançou a ideia de criar uma APAE no município. De acordo com a ata da instituição, a fundação da APAE local ocorreu no dia seis de setembro de 1977, pouco mais de um ano após o início da classe especial na escola municipal já mencionada, sobre presidência de Maria Luiza Santana e secretaria de Olívia Flora Petreski de Siqueira ${ }^{9}$.

As duas professoras também comentaram sobre o espaço físico onde os alunos eram atendidos antes do surgimento da APAE e, dessa forma, Santana relatou que:

[...] era uma escola de madeira e tinha uma casa, assim, tudo anexo, era num terrenão só, tinha as salas de aula e uma casa. Eles [alunos] eram atendidos nessa casa, porque não tinha sala suficiente, quando eu cheguei aqui já era assim, a sala especial já era nessa casa do colégio Marechal Rondon (SANTANA).

Tal relato foi confirmado em uma frase clara e objetiva da Elerbrok: "Era uma sala normal, de madeira, não tinha nada de especial não". Cabe salientar que a Escola Municipal Marechal Rondon foi a primeira instituição educacional do município de Naviraí e começou a ser construída em 1956 (NAVIRAI, 2017). De acordo com a descrição de Santana, tratava-se de uma grande escola de madeira, com ensino comum, localizada no centro da cidade.

\footnotetext{
${ }^{8}$ Atualmente EMEF- Escola Municipal de Ensino Fundamental Marechal Rondon, funcionando em outro endereço, com oferta de Ensino Fundamental e Educação de Jovens e Adultos.

9 Professora da classe especial em Naviraí na década de 1970. Trabalhou junto com Maria Luiza Santana e Lourdes Elerbrok e ajudou a fundar a APAE do município.
} 
Em relação à quantidade de alunos, bem como aos tipos de deficiências que eram mais frequentemente atendidos na classe especial, a professora Santana diz que "A principal deficiência era a deficiência mental. É... a principal era a deficiência mental e a Síndrome de Down que tinha também e alguns com paralisia cerebral, alunos com paralisia cerebral severa." A professora Elerbrok reforça a ideia ao afirmar que "Atendia-se a deficiência leve, porque não tinha condições de atender uma deficiência mais [severa] não tinha estrutura. "

É interessante notar que, mais uma vez, os depoimentos das professoras relacionam-se com a realidade nacional, visto que, conforme Miranda (2008), foi na década de 1970 que a luta pela integração dos ditos "deficientes mentais"10 ganhou força, fazendo com que a Educação Especial tivesse mais visibilidade frente às secretarias educacionais.

Miranda (2008, p. 37) também enfatiza que o atendimento em classes especiais no Brasil, nos anos de 1970, era para alunos com deficiências vistas como leves, incluindo as "[...] dificuldades de aprendizagem, distúrbios de comportamento e deficiência mental leve". Já os alunos com deficiência entendidas como graves iam para as escolas especiais, o que até então não existia no município de Naviraí. Segundo os relatos das entrevistadas, a classe especial existente na Escola Marechal Cândido Rondon atendia somente pessoas com deficiência intelectual, pois não havia espaço nem material adequado para atender outras deficiências na escola.

No que se refere à quantidade de professores que trabalhavam na classe especial, Elerbrok recorda que "Tinha na faixa de quinze alunos, cada período, tinha dois períodos na época" e poucas professoras. De forma mais precisa, Santana salienta:

[...] no início que era a classe especial, nós éramos três. Era eu, a Olivia e a Lourdes. Então depois, aí veja bem, foi criada a APAE. É... eu fui a primeira presidente. Nesse sentido, da formação da entidade, sabe?! Só que depois eu fui embora, a comunidade deu continuidade e depois construíram a escola e tudo mais.

${ }^{10}$ Atualmente, designadas como pessoas com deficiência intelectual. 
Ao comentar sobre a formação dos professores que inicialmente trabalhavam com a Educação Especial antes de 1986, Santana destaca:

Eu vim com especialização na área, né, e elas [outras duas professoras] tinham formação que... a Lourdes, por exemplo, eu conheci a Lourdes quando ela foi para Cuiabá fazer os cursos, que eram cursos que davam, eles davam cursos tipo extensão, pra preparação dos professores.

Ao passo que Elerbrok relatou:

Tínhamos, todas três tínhamos formação. Nós fizemos um curso. A Maria Luiza Santana ela já veio do Paraná, onde ela trabalhava em uma APAE lá. E eu e a Olivia, em 76... não, não foi em 76 que começou não, foi em 77, porque em 76 nós ficamos de outubro a dezembro em Cuiabá, fazendo um curso de especialização, era um curso intensivo de especialização pra classes especiais.

Almeida (2004), em um breve estudo sobre a formação de professores no campo da educação especial, salienta que os primeiros cursos intensivos nesta área, de nível médio, eram oferecidos em institutos federais e reuniam professores de vários estados, e devido a essa organização, a carga horária era incerta.

No final dos anos de 1960, o Conselho Federal de Educação (CEF) emitiu um parecer defendendo que a formação de professores de Educação Especial fosse elevada a nível superior, conforme destaca Almeida (2004, p. 6): "a formação para professores de Educação Especial que atuavam na rede regular de ensino passa a ser obrigatória em nível universitário, ou seja, Pedagogia com Habilitação em Educação Especial, que poderia ser numa área especifica". Entretanto, muitos Estados continuaram com os cursos de especialização, sem atender a essa orientação.

De acordo com uma publicação do Jornal O Estado de Mato Grosso, ocorreu em outubro de 1975, em Cuiabá, um seminário para debater sobre as reformas que estavam ocorrendo no ensino desde 1971. Entre as mudanças ocorridas na reforma e debatidas naquela ocasião, incluía-se a Educação Especial e o problema dos Excepcionais. No evento, que foi aberto ao público, participaram autoridades, professores e dirigentes de instituições de ensino (REFORMA..., 1975). 
Em janeiro de 1976 ocorreu, também em Cuiabá, o $1^{\circ}$ Encontro de Administração Escolar em Educação Especial, promovido pela Secretaria de Educação e Cultura em parceria com Centro Nacional de Educação Especial - CENESP, que buscava fornecer um auxílio aos interessados em desenvolver programas de Educação Especial. O encontro reuniu pessoas de várias cidades do estado de Mato Grosso, que já trabalhavam na área em seus respectivos municípios e discutiram os temas, metodologia de trabalho, Psicologia, reabilitação do excepcional, causas da excepcionalidade e relações humanas (MATO GROSSO, 1976).

Face ao exposto, segundo os relatos das professoras, entende-se que o curso realizado em Cuiabá poderia ser um intensivo como os elucidados por Almeida (2004), assim como alguma edição do Encontro de Administração Escolar em Educação Especial.

A década de 1970 foi realmente marcada como um grande avanço nas Políticas Públicas na Educação Especial, com a criação de Serviços que beneficiam as pessoas com deficiência dentro das Secretarias Estaduais de Educação (CAPELLINE; MENDES, 2006). Nesse sentido, as participantes da pesquisa comentaram sobre incentivos do governo para a classe especial que funcionava no município:

\begin{abstract}
Não, na época não. Era uma classe comum, era dentro da escola, a verba que vinha era pra toda a escola. Aí, com a criação da APAE, a APAE começou a ajudar a classe especial, então eles começaram a investir na classe especial. Em comprar materiais específicos, mas foi através da APAE, o governo era pra todas as classes, classe normal (SANTANA).
\end{abstract}

Não, naquele tempo, o governo aqui era de Cuiabá. Pra você ir daqui pra Cuiabá era um drama. Então não havia incentivo nem de prefeitura, nem de... O governo do Estado que deu esse curso pra gente, através da secretaria do estado do Mato Grosso e a gente veio de lá com a intenção de trabalhar e montamos a sala no início do ano. O material pedagógico era nós que fazíamos e com um pouco da experiência que a Maria Luiza tinha, a gente foi montando a coisa. Naquela época não existia esse negócio de incentivo para escola. A escola era mantida, os professores eram mantidos, material pedagógico não existia, a gente que fazia, do bolso da gente também e não existia esse negócio de incentivo financeiro. Então se o professor quisesse tinha, se não quisesse não tinha (ELERBROK). 
As classes especiais funcionavam em escolas de ensino regular (LIMA, 2010), o que condiz com o relato das professoras ao afirmarem que a verba financeira recebida era de toda a escola e, segundo elas, não era o suficiente para investir na classe especial. Sendo assim, ficava na responsabilidade das professoras conseguir o material pedagógico para ministrar as aulas, realidade que só mudou a partir de 1977 com a criação da APAE de Naviraí, que passou a contribuir e apoiar a classe especial do município. De acordo com Lima (2010), os professores de classe especial recebiam uma gratificação de vinte por cento, informação que não foi mencionada pelas entrevistadas.

As participantes da pesquisa também comentaram sobre como era visto o ensino de pessoas com deficiência naquela época, principalmente se havia algum tipo de preconceito. A professora Santana aproveitou para fazer um desabafo narrando que quem mais segregava, e que ainda segrega, é o próprio governo. Ela também considera que o ensino voltado a pessoas com deficiência precisava de uma equipe qualificada, com médicos e materiais que ajudassem a desenvolver as potencialidades dos alunos. Mas a classe especial segregava ainda mais, já que não tinha recursos adequados para atendê-los, além do fato de que a maioria dos alunos recebidos na escola eram os considerados "difíceis" de se trabalhar na classe comum. Para Rogalski (2010), muitos dos alunos atendidos nem eram, na realidade, público a ser encaminhado para classes especiais.

Dessa forma, a entrevistada defende a criação das APAEs no país, salientando que a APAE existe para oferecer atendimento especializado, não para segregar, o que condiz com legado das APAEs em fornecer educação, saúde e assistência social às pessoas com deficiência (LANNA JUNIOR, 2010). A professora Elerbrok, no entanto, é mais direta em sua resposta, dizendo que o preconceito:

[...] sempre existiu né?! Porque o pessoal não entendia como havia crianças especiais, então eles achavam estranho ver uma pessoa daquela, achava que ela não aprenderia nada, umas coisas assim. Tinha bastante criança. E era assim que funcionava, bem precariamente.

Pode-se entender, de acordo com o depoimento e com as mudanças ocorridas naquele período em benefício às pessoas com deficiência, que o 
preconceito tenha diminuído, ou pelo menos permaneceu velado, já que uma das entrevistadas destacou que alguns professores de classes comuns não tinham interesse em juntar-se ou auxiliar na classe especial.

Outro questionamento que surgiu durante a entrevista com Santana foi a respeito da organização no atendimento, se os alunos ficavam todos juntos, e ela então relatou:

[...] a gente se virava sozinha na verdade, porque o restante que tinha agia tipo "ah, eu não entendo", então, a gente se organizou no seguinte sentido, como a gente atendia vários, cada professor pegou um grupinho, a turminha tipo préescola, a turma de alfabetização, e a turma mais velha, que também tinha toda essa parte. Mas assim, de profissionalização quero dizer, que não era uma profissionalização, mas assim, mais atividades manuais, higiene. As meninas, por exemplo, além da alfabetização, a gente ensinava fazer bolo, limpeza de casa, limpando a própria sala e etc., a gente fazia um tipo de trabalho.

Pelo depoimento de Santana, entende-se que o ensino na classe especial da escola Marechal Rondon era limitado e as professoras trabalhavam com o pouco recurso que possuíam, além de ensinar às meninas atividades domésticas, um ato involuntário que reforçava a descriminação sexista na época (SENKEVICS, 2014). Mas, na realidade, a classe especial deveria ensinar o conteúdo escolar de acordo com as especificidades de cada aluno, considerando as limitações e utilizando recursos pedagógicos apropriados, assim como o espaço (MELETTI; LIDUENHA, 2009).

Para finalizar a entrevista, foi indagado se havia algo a mais que era importante destacar sobre o seu trabalho desenvolvido na época. A professora Elerbrok destacou como eram realizadas as atividades, relembrando que:

É importante falar dos trabalhos que a gente fazia com os alunos, a gente ensinava eles a fazer trabalhinhos com macarrão, com tampinha, umas coisas assim, bem rudimentar mesmo, mas a gente ensinava eles fazerem, aqueles tapetinhos de pôr na porta, com tampinha, época de natal, aquelas árvores de natal, feitas com cone e macarrão. Enfim, era bastante rudimentar. E aí a gente foi tocando a classe assim dessa forma, até que em 1986 quem assumiu a presidência..., porque esse tempo todo nem eleição teve, ficou parada a APAE, sabe. Teve uma primeira eleição 
quando fundaram a APAE em 1977 e depois ninguém mais avançou. Em 1986 assumiu a presidência da APAE o professor Valdemiro, que é o Valdemiro Araujo de Souza e ele se interessou em montar a escola, porque tinha muita criança com muita deficiência, não era só a deficiência leve. $E$ aí fundou a $A P A E$, conseguiu com o Estado sete professores, entre eles eu estava. E aí eles falaram com o prefeito, e o prefeito arrumou aquela escola que está funcionando a APROCAN11, lá na avenida Pantanal, que era também uma situação precária. Mas a gente foi para lá e a partir daí é que se começou o trabalho realmente da escola da APAE. Começou em junho de 1986.

Em conformidade com o relato de Elerbrok, a ata de fundação do CEDEN $^{12}$ atesta que este foi criado no dia 19 de junho de 1986, e passou a funcionar provisoriamente em um prédio na avenida Pantanal. A partir de então, a escola para pessoas com deficiência estava iniciada, com oferta de ensino na Educação Infantil e Ensino Fundamental, sendo mantida pela APAE até os dias atuais, atualmente com instalações próprias.

\section{Considerações Finais}

Tendo em vista que a pesquisa realizada teve por finalidade fazer um estudo histórico da Educação Especial em Naviraí, a fim de entender como era oferecida a educação formal às crianças com deficiência no período de 1963 a 1986, desde a emancipação municipal até a implantação do CEDEN pela APAE, diante das análises realizadas, relatamos que o povoado, então chamado de Vera Cruz, começou a ser colonizado em 1952. Quatro anos depois surgiram as primeiras salas de aula e, em 1958, tornou-se distrito de Caarapó, passando a se chamar Naviraí.

Em 1963 ocorreu a emancipação e Naviraí se tornou município, mas o ensino voltado ao atendimento das crianças com deficiência só começou a ser oferecido em 1976, em uma classe especial anexa à escola municipal Marechal Rondon. Todas as crianças que apresentavam deficiência

\footnotetext{
11 Associação dos Protetores de Crianças e Adolescentes de Naviraí - APROCAN. Localizada na Avenida Pantanal, no 660, Varjão.

12 Atualmente localizado na Avenida Mato Grosso, no 1385.
} 
frequentavam a mesma sala, independentemente das especificidades de sua condição, predominando a deficiência intelectual.

As duas professoras entrevistadas para este estudo, Santana e Elerbrok; fizeram parte dessa História, visto que foram as primeiras a participar de um curso de formação em Cuiabá, ao final de 1975, alguns meses antes da implantação da classe especial e, consequentemente, eram as profissionais que trabalhavam com os alunos que tinham algum tipo de deficiência. Essas atividades começaram, de certa forma, no improviso e sem muita estrutura.

De acordo com as análises realizadas, evidencia-se que o município começou a se dedicar à educação da criança com deficiência no mesmo período em que o país também investia nesta área, sob a égide da integração, e, desde essa época, ocorreram muitos avanços na Educação Especial e na Educação Inclusiva, tanto em âmbito nacional, quanto municipal. Na atualidade, a APAE e o CEDEN funcionam no mesmo endereço, em Naviraí, com atendimentos voltados para crianças e adultos com deficiência intelectual.

Por fim, destaca-se a importância de resgatar o histórico da Educação Especial em Naviraí, por meio dos relatos das professoras Santana e Elerbrok, que foram protagonistas de todo o processo embrionário e origem da Educação Especial no município, cujas histórias de vida se entrelaçam com a de Naviraí. Hoje, elas se caracterizam, portanto, como pessoas que narram e contam histórias a partir dessas memórias de trabalho docente, permitindo, na ausência de documentos escritos e de outros registros históricos, a compreensão de como se configurou, nessa localidade, o atendimento educacional à pessoa com deficiência.

\section{Referências}

ALMEIDA, Maria Amélia. Formação do professor para a educação especial: história, legislação e competências. Revista Educação Especial, Santa Maria, n. 24, p. 1-7, 2004. 
BRASIL. Constituição (1988). Constituição da República Federativa do Brasil. Disponível em:

<https://www.senado.leg.br/atividade/const/con1988/con1988_14.12.2017

/CON1988.pdf>. Acesso em: 20 jan. 2017.

BRASIL. Lei n. 10.436, de 24 de abril de 2002. Dispõe sobre a língua brasileira de sinais. Brasília: CN, 2002. Disponível em:

<http://www.planalto.gov.br/ccivil_03/leis/2002/L10436.htm>. Acesso em: 20 jan. 2017.

BRASIL. Lei n. 13.146, de 06 de julho de 2015. Institui a lei brasileira de inclusão da pessoa com deficiência. Brasília: CBIA, 2015.

BRASIL. Lei n. 13.409, de 28 de dezembro de 2016. Altera a Lei n. 12.711, de 29 de agosto de 2012, para dispor sobre a reserva de vagas para pessoas com deficiência nos cursos técnico de nível médio e superior das instituições federais de ensino. Brasília: CBIA, 2016.

BRASIL. Lei n. 5.626, de 22 de dezembro de 2005. Regulamenta a Lei n. 10.436, de 24 de abril de 2002, que dispõe sobre a Língua Brasileira de Sinais - Libras, e o art. 18 da Lei n. 10.098, de 19 de dezembro de 2000. Brasília: CBIA, 2005.

BRASIL. Lei n. 8.069, de 13 de julho de 1990. Dispõe sobre o estatuto da criança e do adolescente. Brasília: CBIA, 1990.

BRASIL. Lei n. 9.394, de 20 de dezembro de 1996. Estabelece as diretrizes e bases da educação nacional. Disponível em:

<http://www.planalto.gov.br/ccivil_03/leis/I9394.htm>. Acesso em: 20 jan. 2017.

BRASIL. Lei no 4.024, de 20 de dezembro de 1961. Fixa as diretrizes e bases da educação nacional. Disponível em:

<http://www.planalto.gov.br/ccivil_03/leis/L4024.htm>. Acesso em: 20 jan. 2017.

BRASIL. Lei no 7.853, de 24 de outubro de 1989. Dispõe sobre o apoio às pessoas portadoras de deficiência, sua integração social, sobre a Coordenadoria Nacional para Integração da Pessoa Portadora de Deficiência. Disponível em: <http://www.planalto.gov.br/ccivil_03/leis/L7853.htm> . Acesso em: 20 jan. 2017.

BRASIL. Lei n05. 692, de 11 de agosto de 1971. Fixa as diretrizes e bases para o ensino de $1^{\circ}$ e $2^{\circ}$ graus. Disponível em:

<http://www.planalto.gov.br/ccivil_03/leis/L5692.htm>. Acesso em: 20 jan. 2017.

BRASIL. Ministério da Educação. Política nacional de educação especial na perspectiva da educação inclusiva. 2008. Disponível em:

<http://portal.mec.gov.br/arquivos/pdf/politicaeducespecial.pdf>. Acesso em: 20 jan. 2017. 
BRASIL. Resolução CNE/CEB n. 2, de 11 de setembro de 2001. Institui diretrizes nacionais para a educação especial na educação básica. Disponível em: <http://portal.mec.gov.br/cne/arquivos/pdf/CEB0201.pdf>. Acesso em: 20 jan. 2017.

CAPELLINI, Vera Lucia Messias Fialho; MENDES, Enicéia Gonçalves. História da educação especial: em busca de um espaço na história da educação brasileira. In: SEMINÁRIO NACIONAL DE ESTUDOS E PESQUISAS, 7., 2006, Campinas. Anais... Campinas: FAEPEX - UNICAMP, 2006. v. 1.

IBGE. Cidades. Brasil. Mato Grosso do Sul. Naviraí. 2017. Disponível em: <https://cidades.ibge.gov.br/brasil/ms/navirai/historico>. Acesso em: 20 jan. 2017.

JOSSO, Marie-Christine. A transformação de si a partir da narração de histórias de vida. Educação, Porto Alegre, RS, ano 30, n. 3, p. 413-438, set. /dez. 2007.

LANNA JÚNIOR, Mário Cléber Martins. História do movimento político das pessoas com deficiência no Brasil. Brasília: Secretaria de Direitos Humanos, Secretaria Nacional de Promoção dos Direitos da Pessoa com Deficiência, 2010.

LIMA, Priscila Augusta. Classe especial. In: OLIVEIRA, Dalila Andrade; DUARTE, Adriana Maria Cancella; VIEIRA, Lívia Maria Fraga. Dicionário: trabalho, profissão e condição docente. Belo Horizonte: UFMG/Faculdade de Educação, 2010. 1 CD-ROM.

MATO GROSSO. Secretaria de Educação e Cultura. Centro Nacional de Educação Especial - CENESP. Primeiro Encontro de Administração Escolar em Educação Especial. Cuiabá, MT, 1976.

MAZZOTTA, Marcos José da Silveira. Educação especial no Brasil: história e políticas públicas. 5. ed. São Paulo: Cortez, 2005.

MELETTI, Silvia Marcia Ferreira; LIDUENHA, Taisa Grasiela Gomes. Percurso escolar dos alunos de classe especial que hoje frequentam a educação de jovens e adultos (EJA): Universidade Estadual de Londrina (UEL). In: CONGRESSO BRASILEIRO MULTIDISCIPLINAR DE EDUCAÇÃ̃O ESPECIAL, 5. Londrina. Anais... Londrina: UEL, 2009. Disponível em:

$<$ http://www.uel.br/eventos/congressomultidisciplinar/pages/arquivos/anai s/2009/277.pdf>. Acesso em: 25 set. 2017.

MENDES, Enicéia Gonçalves. Breve histórico da educação especial no Brasil. Revista Educación y Pedagogía, Medellín, v. 22, n. 57, p. 93-109, mayo/ago. 2010.

MIRANDA, Arlete Aparecida Bertoldo. Educação especial no brasil: desenvolvimento histórico. Cadernos de História da Educação, Uberlândia, n. 7, p. 29-44, jan./dez, 2008. 
MÜLLER, Tania Mara Pedroso. A primeira escola especial para "creanças anormaes" no Distrito Federal: o Pavilhão Bourneville (1903-1920). Revista Brasileira de Educação Especial, Bauru, v. 6, n. 1, p. 79-97, 2000.

NAVIRAÍ. Prefeitura Municipal. História de Naviraí: origem do nome. Disponível em: <http://www.navirai.ms.gov.br/pagina/paginas/3-historiade-navirai>. Acesso em: 20 jan. 2017.

REFORMA do ensino: debate na câmara amanhã. O Estado de Mato Grosso, Cuiabá, MT, 26 out. 1975, ed. 07209, p. 3. Nacional. Disponível em: <http://memoria.bn.br/DocReader/DocReader.aspx?bib=098086\&PagFis $=2$ 4504\&Pesq=educa\%C3\%A7\%C3\%A30\%20especial >. Acesso em: 20 jan. 2017.

RODRIGUES, Olga Maria Piazentin Rolim. Educação especial: história, etiologia, conceitos e legislação vigente. In: CAPELLINI, Vera Lucia Messias Fialho (Org.). Práticas em educação especial e inclusiva na área da deficiência mental. Bauru: MEC/FC/SEE, 2008.

ROGALSKI, Solange Menin. Histórico do surgimento da educação especial. REI: Revista de Educação do IDEAU, Bagé, RS, v. 5, n. 12, p. 1-13, jul./dez. 2010.

SENKEVICS, Adriano. Gênero e educação: uma história de desigualdades. 2014. Disponível em: <https://ensaiosdegenero.wordpress.com/2014/01/22/genero-e-educacaouma-historia-de-desigualdades/>. Acesso em: 20 jan. 2017.

SILVA, Larissa Maciel Gonçalves. Educação especial e inclusão escolar sob a perspectiva legal. In: SIMPÓSIO INTERNACIONAL ESTADO E POLÍTICAS DA UNIVERSIDADE FEDERAL DE UBERLÂNDIA, 5., Uberlândia. Anais... Uberlândia: UFU, 2009. Disponível em:

<http://www.simposioestadopoliticas.ufu.br/imagens/anais/pdf/BP05.pdf>. Acesso em: 20 jan. 2017.

SILVEIRA, Denise Tolfo; GERHARDT, Tatiana Engel. Métodos de pesquisa. Porto Alegre: Ed. da UFRGS, 2009.

SOUZA, Elizeu Clementino de. A arte de contar e trocar experiências: reflexões teórico-metodológicas sobre história de vida em formação. Revista Educação em Questão, Natal, v. 25, n. 11, p. 22-39, jan./abr. 2006. 